\title{
Nomes Paiter Suruí: metáfora? Sugestões para a pesquisa pela atual geração de intelectuais Paiter
}

\author{
Nouns in Suruí Paiter: metaphor? Suggestions for research by \\ the present day generation of intellectual Paiter
}

Betty Mindlin ${ }^{1}$

Uraan Anderson Suruí ${ }^{2}$

\begin{abstract}
Resumo
Este artigo sumariza algumas sugestões para atualização da pesquisa realizada por Betty Mindlin em 1980, com dados coletados até o início dos anos 2000, jamais publicados, sobre o significado dos nomes Paiter Suruí e sobre o sistema de nominação neste povo. Hoje contamos com as novas gerações de intelectuais Paiter como os principais pesquisadores, assim como os pajés, os quais poderão participar também como conhecedores de épocas antigas. Uma das importantes sugestões é investigar se a antiga tradição de nomear continua produtiva e em que proporções a tradição nacional a tem influenciado.
\end{abstract}

Palavras-chave: Metáfora. Sistema de nomeação. Interferências externas.

\begin{abstract}
This article summarizes a few suggestions to verify and update the research on the meaning of Paiter names and their nomination system initiated in 1980 and continued up to 2000 by Betty Mindlin. Nowadays there is a new generation of Paiter intellectuals, who are in touch with a few older pajés, who may contribute with their knowledge of ancient times. One of the important suggestions is to investigate if the old tradition of naming is still productive, and to what extent the the national Brazilian tradition influences it.
\end{abstract}

Keywords: Metaphor. Paiter nomination system. External interferences.

O tema dos nomes e das regras de nominação fascina no universo indígena ou em geral na humanidade, com um amplo leque de sistemas diferentes. Ao final dessa exposição procurarei evocar alguns exemplos que se contrapõem à visão uniformizadora que costumamos ter. Pois tomamos o padrão hegemônico como único e natural, esquecendo o quanto cada um é importante para a afirmação de um povo.

\footnotetext{
${ }^{1}$ Doutora em Antropologia pela PUC-SP (Pontifícia Universidade Católica de São Paulo), 1984, autora de 6 livros em coautoria com narradores indígenas, além de outros livros como Diários da Floresta, Terceiro Nome, 2006.

${ }^{2}$ Graduando do Intercultural Indígena da UNIR.
} 
Comecei a estudar significados dos nomes e o sistema de nominação Paiter desde os anos 80, mas não estendi a reflexão e pouco publiquei. Uraan Anderson Suruí e eu pensamos em atualizar essa pesquisa, que agora pode ser feita pelos próprios Paiter com muito mais profundidade e conhecimento. Interessante é investigar se a antiga tradição permanece e como os nomes nacionais a influenciam. Este trabalho aqui apresentado é, assim, meu e de Uraan, mas é ainda um esboço, quase que um roteiro de pesquisa para todos, a partir do que é incompleto e talvez impreciso ou errôneo. Os Korubey Paiter (Mais Velhos, Sábios, Longevos) serão os juízes e professores de agora.

Vamos começar por exemplos de nomes e de famílias de nomes. Havia uma tradução, feita por mim, por Antonio Ipokarã Suruí e outros, de cerca de 360 nomes. Uraan e eu revimos uns 60 e acrescentamos outros 20; o processo é trabalhoso, pode ser poético, resultar em haikais. Não vamos percorrer todos, para não ouvir roncos no auditório e mudarmos nossos nomes para Aquele ou Aquela que Aborrece e Adormece. Aquela Que Desata em Fuga o Auditório... Pois o número de nomes é muito maior que o de pessoas.

Isso porque cada homem ou mulher Paiter tem vários nomes. Para a mulher são as avós materna ou paterna ou a tia paterna que nomeiam; para o homem, os avôs, materno ou paterno, e o tio materno. Uraan e seu pai podem oferecer comentários, bem como outros Koryp ey. Uraan e eu divergimos um pouco em nossa conversa de abril de 2014 em São Paulo - ou eu me enganei ou houve mudança de conhecimento ou hábitos nesse tempo. É possível que avôs e avós classificatórios também possam nomear? Pais e mães não nomeiam.

Há regras e interdições para pronunciar os nomes. Grave transgressão é filhos falarem o nome de pais, mães, (talvez também dos avós?). Não se deve pronunciar o nome de irmãos mais velhos (dos classificatórios também?). Os irmãos ou irmãs mais velhos podem chamar os mais novos pelo nome (ou pelo vocativo para essa categoria, ongarmey - o vocativo sempre é permitido. Os mais novos devem chamar os irmãos usando o termo ongoronam). No meu trabalho de detetive começando a aprender a língua, os vocativos é que me guiaram a construir o sistema de parentesco e a perguntar os nomes à pessoa certa, e não a quem não pode falar. Em determinadas categorias de parentesco, é possível dizer o nome de parentes afins, o dos consanguíneos não. A própria pessoa não pode falar seu nome. Velhos e velhas têm todos os tabus relaxados, contam nomes de quem morreu, o que é proibido aos demais - provavelmente porque se evocadas, as almas, paixo, poderiam voltar (este assunto complexo não pode ser discutido nesta fala, exige outra ocasião).

Vejamos exemplos de nomes, os que Uraan e eu percorremos juntos, corrigindo os que estavam arrolados antes e traduzindo alguns outros da Linha 14. Será preciso atualizar a ortografia. Uma filigrana seria comparar nomes de uma mesma pessoa, examinando se há alguma característica de quem dá o nome. 
Sugiro que Uraan e outros escolham um grupo de nomes e destrinchem as raízes em Tupí-Mondé, expliquem-nos melhor. Cada letrado ou letrada Paiter poderia encarregar-se de dez nomes, por exemplo os de parentes bem próximos.

Façamos uma seleção de nomes aparentados à primeira vista - poderíamos indagar se sua propriedade é de alguns clãs ou núcleos familiares, algo que não sabemos. Entre parêntesis estão o clã, o sexo e a data de nascimento.

\section{Femininos:}

Com So ou Ho (segundo a pronúncia de diferentes aldeias): "So" são "algo": bens, coisas, matéria, mas também seres, como os do além - podem ser objeto ou podem ser semelhantes a alma, ao imaterial.

Sobitchab Tem casa cheia de coisas (f Gamep 1985)

Hobira Cheia de coisas, tira muita comida da roça (f Gamep 1969)

Hobiaba Lavadeira, mulher que lava muito (f Kaban 1962)

Solor Coisa Feia (lor, feio) outro nome de Mangarangaba (f Gamep 1981)

Somam Sovina, Esconde tudo (“mamim", esconder) (f Gamep 1988)

Somaor Traz sempre comida e dá para todos (f Gamep 1988)

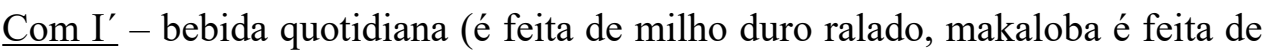
milho verde)

Imatchug A que fura a bebida, abre a tampa da panela para a fartura começar; A fazedora de furo para a bebida escoar, a que abre a tampa-palha da panela da bebida; Que fura o ímataga, furar a bebida, abrir a panela, a tampa (f Kaban 1989)

Imandjui Chiado de bebida quando se põe panela no fogo (f Kaban 1978)

Ixiboga Espuma da Sopa Fervente (f Gapgir 1975)

Ítiaed Dona da bebida (f Gamep 1965)

Isor Quem cozinha makaloba podre, bebida com mau cheiro (f Kaban 1983)

\section{Mapid (com criança)}

Mapidamixid Filhos mexem muito, dão muito trabalho, preocupada com tantas tarefas (f Gamep 1986)

Mapidatchor Tem filho do qual se orgulha, Feliz com seu filho ( $\mathrm{f}$ Gamep 1989)

Mapirikin Boa Parideira, Partos Fáceis (f Kaban 1966)

Mapidawei Banha Criança (f Gamep 1987) 
Waled ou Ualed, Mulher

Walesiab Mulher Molhada (f Kaban 1949)

Waledibi, Paibi mulher sempre grávida: Onde a gente sempre dorme (f Gamep 1988)

Goptingwaled, Iperehor Mulher que fia, Menina brava (f Gapgir 1974)

Waledaiter, Waledewaíter, Mabepidjá Mulher quer namorar muito, A que segura com a mão (f Gapgir 1985)

Waledergoen, Upereon Mulher com corpo fino (f Makor 1933)

Outros:

Weitã

A Que Esquenta Água, Toma Banho de Água Quente, (f Kaban f 1946)

Gobatan $\quad$ Fuso forte, duro, de madeira dura (f Kaban 1984)

Moitiri assa muita mandioca, ajuda muita gente, mão aberta ( $\mathrm{f}$ Kaban 1981)

Pamoga Nossa casa sempre fecha (mogá, pogá, fechar) (f Gamep, 1973)

Pamaixod Todas as nossas coisas (Gapgir $\mathrm{f}$ 1950)

Pamalodnag (mulher de Uraan) Mulher Provedora (f Kaban 1991)

Pangopurã Aquela que fala muito quando filho nasce, A Que Fala Eufórica Porque Pariu Filho; Quando Filho Nasce Falamos Muito! (f Kaban 1968)

Lakabateri Olhos muito bonitos (f Kaban 1949)

Mangarangaba A que faz Lindos Colares. Outro nome é Solor (f Gamep 1981)

Mangargatad Cortadora de colar (katad, cortar)

\section{Masculinos}

Naraí o cetro sagrado do pajé, uma taquara coroada com duas penas vermelhas de arara e duas pequenas de harpia

Naraxar $\quad$ Famoso (outros nomes Iablar, Perpera) (h, Kaban 1952)

Naraeixotoi É como o "naraí", cetro do além mastigando ervas magas de cura, alimento precioso para curar, invocação para outro ser não fazer mal (h Gamep 1980) Naraeixotoi foi o primeiro Paiter a nascer de cesariana, também se chama Gapamne, Roça Nova

Naraiolen Lugar do naraí (h, Kaban 1985) 
Naraikopega boca do naraí, aquele que grita ao falar, naraí invoca os espíritos cantando, gritando (h, Gamep 1977)

Naraikoalab, Gaxor Quando canta escuta-se muito longe, grito que se ouve muito longe. Seu outro nome é Gaxor, Roça feia (h Kaban 1980)

Naraieor $\quad$ Pessoa que traz o naraí (h, Kaban 1988)

Lab, casa, Pa nossa:

Labiwai Chefe da Casa (h Gamep 1971)

Lamishab Casa Cheia Casa Movimentada, (h Gamep 1985)

Labmã $\quad$ Faz muita casa (h Kaban 1977)

$\underline{\text { Iab, flecha, Ib árvore }}$

Iablar Flecha Pendurada, Naraxar, Perpera (h, Kaban 1952)

Iablegar Pena da flecha cai, (legar, pena) (h Kaban 1983)

Ibtabira (outro nome Gapoy) Toco de árvore (h Kaban 1952)

Ihibepuia, Pawatã Árvore Frondosa (ipibe) (h K 1954 falecido 78)

Maribago Assobio da Árvore Derrubada pelo Vento (h Kaban $\mathrm{h}$ 1931)

Mopid, caça

Mopidangop Tem Ciúme da Caça, Não Dá Caça a Ninguém (alakob ciumento) (h Gamep 1986)

Mopidgar $\quad$ Ó Caça que me Escapa, Caça Em Fuga, Caça Não Morreu (h Gamep 1988)

Mopiri Flechadas Infalíveis, Flechas Que Sempre Matam Os Bichos, (h Gamep 1965)

Mopinmoehor Caçador das Flechas que Sempre Atingem, Quando o Bicho é Flechado Grita de Dor (h Kaban 1986)

Mopidaar Bicho que Cai, Bicho que Foi Flechado, Moço Bom Caçador, Dono dos Animais Sempre Flechados (h Gamep 1983)

Mopidakabá Lugar onde sempre se mata (h Gamep 1988)

Mopidapenem Bicho que rola ao cair, quando se atira no bicho, caça cai rolando (h Kaban 1988)

Mopidakabura o que amontoa a caça que matou (h Kaban 1970) 


\section{Pawá, Nossa casa}

Pawá Nossa casa (h Kaban 1982)

Pawahib Esteio da Nossa Casa (h Gamep 1944)

Pawatã (outro nome Ihibepuia) Não Sai De Casa, Recluso em Casa

Muito freqüentes os da Roça, Ga; Ga, roça, Gará, Mato:

Gapoy Roça-Grande

Tagata Roça muito pisada, muito cuidada

Gaíwaia Dono da roça

Gapop Roça comprida

Gahega Muito mato na roça

Gawagoten Muito vento na roça

Gatin Muito ciúme da roça

Gapamne Roça Nova

Garaietigom Roça Limpa, Roça Sem Mato

Outros:

Oiômar Homem sempre ausente, roçando, trabalhando (h Gapgir 1955). É pajé

Perpera (outro nome de Iablar) Sempre Girando É pajé

Panarasiboar pajé famoso manda fazer fogueira (panara, pajé famoso, siboar, fogueira) (h Kaban 1980)

Mepoi Caminho grande (h Kaban 1965)

De Diários da floresta (Mindlin 2006):

Há os arcaicos do Arco, Ur:

Urtenera ("O que pendura muitos arcos", "Fazedor das armas")

Urkasotiga ("Aquele cujo arco faz muito barulho quando mata")

Urpingam ("Pegar o arco"),

Urkutanga ("Segurando o arco"),

Urbep ("Arco preto"),

Urapãi ("O arco que acerta bem"),

Uratugare ("Companheiro do arco muito duro"). 
Em Nós Paiter ${ }^{3}$ (Mindlin 1985:94), dou exemplos de traduções de família de nomes, mas não cito o original em Paiter:

Famílias de nomes foram enumeradas, incluindo os de pessoas que já morreram.

Os significados são carregados de poesia: o arco fica nu de flechas de tanto atirar; fala tão bravo que o arco ficará nu de flechas de tanto atirar; nossa casa, casa grande; que faz muitas coisas; carregada de coisas; que faz muito trabalho; o "naraí" não fica parado; o "naraí" que está lá; coisa bonita; tem muito milho na roça; pendurar a rede; morno; flecha que fica escondida; roça grande; tronco; árvore da nossa casa; gavião; bravo; atirar e a árvore cair; pátio grande. Alguns nomes são aparentemente pejorativos: nós trazemos sujeira, porque a criança engatinha e fica suja; feia; roça que fede depois de queimada.

Nomes, portanto, são metáforas. Atribuímos à criança qualidades ou defeitos contidos no significado do nome. Quase sempre são qualidades - poucos os nomes jocosos. Que eu saiba, porém, essas características dos nomes não são categóricas, não são consideradas inerentes à pessoa. $80 ?$

Que conhecimento os Paiter têm hoje das formas de nominação dos anos

Como as regras brasileiras, que são até mesmo legais, levam ao abandono dos costumes antigos? Quem os mantêm?

Hoje é preciso ter sobrenomes - todos usam o mesmo, Suruí ou Paiter em seus documentos. Os Paiter-ey começam a ter propriedades, imóveis urbanos. Embora ainda sejam poucos os proprietários, as casas urbanas vão originar herança. As escolas registram nomes, todos têm documentos de identidade, muitos têm CPF - certificado de pessoas físicas. Nos livros, as mudanças são inúmeras. Não no caso Suruí, mas nos livros dos povos das Terras Indígenas Guaporé ou Rio Branco, os nomes dos povos mudam ano a ano - é o caso do Djeoromitxi ou Jabuti, e das grafias dos outros. Sempre um problema escolher, pois é impossível contentar a todas as opiniões ao mesmo tempo.

\section{Questões a verificar:}

Todas as afirmações feitas acima: a ligação entre os nomes e as características ou feitio das pessoas.

As pessoas não pronunciam o próprio nome.

É possível que avôs e avós classificatórios também possam nomear?

Pais e mães não nomeiam: verificar se isso é correto.

${ }^{3}$ Estou prestes a reeditar Nós Paiter e tornar disponível o livro online para o povo Paiter. Poderemos incluir textos e correções dos Paiter-ey, ao longo do tempo. 
Grave transgressão é filhos falarem o nome de pais, mães, (nomes dos avós também não devem ser pronunciados?). Não devem pronunciar o nome de irmãos mais velhos (classificatórios também?).

Que nomes usam agora, em 2015, as pessoas cujos nomes traduzimos nos anos 90 ? Como se traduzem e se veem hoje?

Transmissão dos Nomes - digo em Nós Paiter, à página 94, que é bom uma pessoa transmitir o próprio nome, que há xarás, mas não tenho provas. Ao contrário, aparentemente não há xarás, "ahed amapi"; todos têm nomes únicos, mas como não conhecemos o conjunto de nomes de uma pessoa, não o sabemos. É uma questão a investigar.

Nomes jocosos, como são dados, são apelido? Jocosos: de caçoada, como Pangoxidjor, Mulher Suja Pelas Fezes da Criança. É caçoada, ou exalta a maternidade?

Uma filigrana seria comparar diferentes nomes de uma mesma pessoa, examinando se cada nome tem características de quem nomeia.

\section{Nominação e outro sistema de vocativos, além do correspondente ao sistema de parentesco}

Em Diários da floresta:

A nominação é um costume fundamental. Quem dá o nome para o menino é o avô materno ou paterno e o tio materno; para a menina, a avó materna ou paterna ou a tia paterna. Uma pessoa pode chamar os adultos ou as crianças que receberam os nomes de seus pais de olop kaled e oni kaled, "quem ganhou o nome de meu pai" e "quem ganhou o nome de minha mãe", e chamam-nas (usam os vocativos) de $b a \mathrm{e}$ aia, papai e mamãe, como se pai e mãe transferissem a relação àqueles a quem deram o nome. Reciprocamente, essas pessoas os chamam de filho e filha.

É outro sistema de vocativos, diferente do comum. No caso de um homem e de uma mulher que sã

o primos cruzados, podem chamar um ao outro de pai e mãe, e pode acontecer também que se casem entre si e se chamem de marido e mulher.

Quando eu ouvia marido e mulher chamarem um ao outro de pai e mãe, não entendia nada. Foi um alívio compreender o sistema superposto pela nominação.

\section{De Nós Paiter:}

Explica-se que uma mulher, por exemplo, Walesiab, chame a filha Hogalaba de mãe: esta foi nomeada pela avó materna, mãe de Walesiab. Mesmo que os avós já tenham morrido quando a criança nasceu, os pais podem chamar os filhos de pai e mãe: é como se, de 
direito, os avós nomeassem os netos, até mesmo do país dos mortos, do Gorakoied. Também a avó ou o avô chamam os netos de mãe e pai, pela mesma razão.

Alguns exemplos podem ajudar a entender:

1) Bani é prima cruzada de Ğahê - sua mãe é irmã classificatória do pai dele e Yamner, pai de Bani, é irmão classificatório da mãe já falecida de Ğahê. Esta mulher nomeou Bani e Ğahê chama Bani de "aia", mãe. Bani chama Ğahê de "mo", fílho, e como ele foi nomeado por Yamner, pai dela, sendo portanto seu pai também de "ba".

2) Cádior é primo cruzado de Paueiika: a mãe dele é irmã do pai dela. O pai de Paueiika nomeou Cádior e Paueiika diz, portanto, que ele é o "o'lop ğaled", o nomeado por meu pai. Ela e seu irmão Ubajara falam "ba", pai, para Cádior; ele lhes responde "paiai", "wai-da", filho, filha, e assim por diante.

Resumindo:

Ego mulher para o menino,

("xíxop ğaled", o nomeado pelo pai dela):

diz "ba" para ele, pai; o menino responde "waid" filha.

Ego mulher para a menina,

("xi-ti-kaled", a nomeada pela mãe dela):

diz "aia" para ela, mãe; a menina responde "waid".

Ego masculino para a menina, ("xi-ti-kaled", nomeada pela mãe dele): diz "aia" para ela; a menina responde "mó", filho.

Ego masculino para o menino, ("xí-xop ğaled, nomeado por seu pai): diz "ba" para ele; o menino responde "paiai", filho.

Esta explicação foi dada pelos Suruí; não funciona no caso do menino nomeado pelo tio materno. Pode ser, de todo modo, que o nomear implique em casamentos futuros, mas isso não foi visto.

Uma outra categoria talvez seja a dos que foram nomeados pelo tio materno ("o'ní soa kaled"). Não parecem existir hoje, mas talvez fossem amigos formais, com obrigações especiais.

Não foi possível descobrir se há uma ocasião ou razão especial para usar esses vocativos no lugar de outros: o uso pode estar relacionado com o ciclo de vida ou outro motivo.

Os nomes são muitos, pelo menos três para cada pessoa. Às vezes são séries longas de cinco ou seis palavras. Os espíritos Ğoanei podem nomear, como uma graça especial. Um menino de dois anos, por exemplo, tem um nome duplo, de um Ğoan cujo cocar mágico, que de tão bonito que é, ao aparecer, faz tudo parar de espanto, até as folhas no ar que o vento derruba das árvores. Filhos de pajé têm nomes doados por Ğoanei, preciosos, dos quais se orgulham. 
Embora o nominador não dê o próprio nome ao nominado e sim, aparentemente, um outro, os nomes parecem ser conservados de pai a filho e de tio materno a sobrinho e o mesmo para as meninas (avó/mãe/ filha; tia paterna/sobrinha). Não está claro se o nome é exatamente o mesmo ou se se trata de uma família de nomes, com um tema central. Aparentemente não há xarás, "a'hed amapi", todos Paiter têm nomes diferentes. Eis um assunto a estudar, pois pouco se percebe à primeira vista: só um dos nomes é mais usado em público e só poucos são dados a conhecer aos estranhos.

Famílias de nomes foram enumeradas, incluindo os de pessoas que já morreram.

Outra coisa interessante:

Diários da floresta:

Há, nesse sistema, uma relação contínua com o mundo dos mortos. Considera-se que mesmo no Gorakoied, no país dos mortos, avôs e avós já falecidos podem nomear as crianças que vão nascendo. Por isso os pais chamam os filhos de pai e mãe, pois os filhos são seus olop kaled e oni kaled, os que ganharam o nome de seu pai e da sua mãe. Os pais são, por sua vez, chamados pelos filhos de paiai e wai, filho e filha. $\mathrm{O}$ avô ou a avó vivos podem chamar o neto ou a neta de pai e mãe - porque estes foram nomeados pelo pai deles, pelo bisavô. Que jogo sofisticado foi desvendar essas regras, apenas ouvindo, sem ninguém que me ensinasse, e que prazer construir essas hipóteses! Precioso foi ver também que esse sistema de nominação, semelhante a um compadrio, origina novos laços e formas de retribuição, de presentes, de produção conjunta.

De Diários da floresta:

Há uma mulher Cinta-Larga chamada Betty (pois os Cinta-Larga não revelam seus nomes indígenas; usam os nossos ou apelidos), o que deu lugar a um utilíssimo comentário de Tikã sobre xarás, abrindo-me portas sobre nomes e sua teoria. Não há xarás (ahed amapi) vivos cada pessoa tem um nome diferente. Um ramo do tesouro intelectual da nominação são os nomes com a mesma raiz, possivelmente dados hereditariamente em certas famílias.

\section{Os nomes: grão para um modo de ser}

"O que há num nome? Aquilo que chamamos de rosa, com qualquer outro nome teria o mesmo perfume."

Shakespeare, Romeu e Julieta 
Em Nós Paiter, no item "Os nomes: grão para o tribal” (p.90-94) desenvolvi as observações sobre o sistema de nominação que origina vocativos diferentes dos utilizados no sistema de parentesco. Sugiro que Uraan verifique essas informações, que repito abaixo.

Ao conhecer alguém, um Suruí pergunta: “quem é teu pai ?", "quem é tua mãe?", "onde você nasceu?", "a que grupo você pertence? (Ğapgir, Ğamep, Makor, Kaban), mas também "quem te deu o nome?" para averiguar o lugar do outro no mundo.

Saber os nomes só ouvindo conversas não seria fácil. Como vimos, muito mais que pelo nome, as pessoas se chamam pela relação que têm entre si, das formas mais variadas. Acompanham sem dificuldade os entrelaçamentos mais prolongados: "filha da irmã do pai dos meus filhos", "irmã mais velha da mãe de meu marido". "Irmã!" ("ub!"), "Irmã mais velha!" (“'Ongóranam!”), "Mãe do menino Fulano!", um irmão pode chamar a irmã, e os termos em Suruí são bem diferentes uns dos outros. Os irmãos homens podem dizer-se "are!" ou "irmão mais velho (novo)". As mulheres podem chamar-se pela relação ou simplesmente "companheira", "are".

Não dizem com frequência o próprio nome, nem gostam de dizer se perguntados. É proibido ("galoba", transgressão) dizer o nome de irmãos (a não ser o de crianças até uns oito anos), o dos pais, o dos avós. Embora não seja propriamente proibido, não se fala o nome do tio materno, da tia paterna, dos cônjuges. Tio paterno e tia materna são chamados de pai e mãe; primos paralelos de irmãos. Primos cruzados podem chamar-se pelos nomes, mas mais comumente usam o termo correspondente ("omaixan!”, "meu primo!"). Cônjuges cuja relação entre si é mais distante que a comum (esta sendo tio materno/filha da irmã ou primos cruzados) usam um termo especial, "nem". Cunhados têm vários termos apelativos: "kokô/onob" (tio materno/sobrinho), em especial " yeey" em oposição a " are". "Are" e "yeey" são formas distintas de companheiro, pois "yeey" é como cunhados se chamam, enquanto "are" é termo usado por irmãos. "Yeey" também é o vocativo do marido para a mulher, quando é o tio materno chamando a sobrinha. Há um termo genérico para sobrinho, homem ou mulher (filho/a do irmão para ego feminino, filho/a da irmã para ego masculino), "o lerat", que é o mesmo para os netos dos dois sexos de ego feminino ou masculino.

Os nomes dos mortos são proibidos, transgressão tão grave pronunciálos quanto o de irmãos ou pais. Ao falar dos mortos, referem-se à relação: "a mãe de fulano". Parece que é perigoso nomear os mortos, que podem puxar para o outro mundo, como que chamados. Algumas pessoas, em especial as mais velhas, se arriscam, sem se preocupar 
muito com a proximidade da morte, e contam com saudade o nome de todos os que já se foram há tempo e a relação dos nomes entre si, os vários nomes do pai e da mãe.

Os nomes são dados para os nenês pequenos, mas não vi a cerimônia.

\section{Observações Finais e Nominação}

Nossa análise demonstra, esperamos, como os nomes criam o Belo: a beleza artística notável no conjunto de costumes indígenas; são comparáveis às nuvens de borboletas, ao espelho dos rios, ao perfume da floresta. Nomes adejam em torno de nós.

Cada povo tem um ou mais sistemas de nominação (como os Paiter Suruí nos ensinam) e assim o assunto é amplo. Exemplos nos levariam a vários dias de exposição. Em $O$ pensamento selvagem, Claude Lévi-Strauss espraia-se em considerações, algumas das quais reproduzidas em Nós Paiter. Carmen Junqueira e os Kamaiurá podem nos contar como os nomes são dados neste povo, de avôs e avós aos netos e netas, enquanto os doadores passam a ter outro nome - há mudanças contínuas, talvez nem sempre hoje obedecidas, para satisfazer os estrangeiros (não índios) que têm dificuldade de aprender até mesmo um nome para cada pessoa.

Nos Amondawa, na Terra Indígena Ureu-au-au, conta-nos Edmundo Peggioni, cada criança passa à próxima que nasce (se for do mesmo sexo) o seu nome, e recebe um novo. Também o pai muda de nome quando o filho mais velho atinge certa idade. As mulheres mudam menos de nome. ${ }^{4}$ Imagine-se a dificuldade que tem um pesquisador incauto para identificar as pessoas...

Em muitos povos jê, como Apinayé, Xavante, Kayapó, a nominação é uma característica comunitária essencial, compreende festas belíssimas, laços rituais importantes entre as pessoas, troca de bens, novas obrigações e dons. Reúne múltiplos aspectos da vida social. Conta-nos Laura Graham sobre os Xavante, no verbete que escreveu para Enciclopédia dos Povos Indígenas no Brasil do Instituto Socioambiental:

O processo de nominação xavante é parte de um sistema complexo de trocas cerimoniais entre as metades, sendo que a literatura registra, inclusive, disputas entre indivíduos pertencentes às metades opostas pela posse de grandes nomes de prestígio. O conjunto de nomes masculinos xavante não só identifica um indivíduo determinado, como se trata de um critério importante para distinguir o pertencimento às linhagens que compõem cada uma das duas metades exogâmicas xavante. Muitas vezes, um homem xavante se identifica a uma linhagem através do reconhecimento de sua filiação a um ancestral que tenha adquirido durante a vida bastante prestígio político. Em

\footnotetext{
${ }^{4}$ Cf. Peggion (2007:123-130).
} 
muitos casos, o nome de maior prestígio desses ancestrais fundadores - um homem xavante pode adquirir até oito nomes durante a sua vida é o mesmo que denomina uma das inúmeras linhagens xavante. Antes da segunda fase de seu processo de socialização - quando se tornam wapté (pré-iniciado, morador na casa de solteiros) - um "menino" xavante é identificado à "linhagem" patrilinear da qual é "herdeiro nominal" por primeiro nome que recebe por volta dos 5 anos.

Na maioria dos casos, esse nomes são "sonhados" por membros da sua linhagem patrilinear. Essa herança será reforçada quando o "menino" passar a ser classificado na categoria de idade dos wapté (pré-iniciado), já que será novamente batizado com outro nome, na grande maioria dos casos, também "sonhado" pelos membros de sua patrilinhagem.

A cerimônia de nominação das mulheres, Pi'õ-nhisi, é uma celebração exclusivamente para elas. Por envolver contatos extra-conjugais, sua prática foi desaprovada por missionários e abandonada por muitos grupos xavante após o contato. Na área de Pimentel Barbosa, ela continuou a ser praticada até meados dos anos 1980, mas não logrou continuidade depois de ser realizada em 1986. Noutras partes, em comunidades que estão afirmando sua independência da influência missionária, ela vem sendo restabelecida."

Ainda um último exemplo é a observação de Darcy Ribeiro sobre a cerimônia de nominação kadiwéu, na qual os nomes deviam ser escolhidos segundo o perfil de personalidade do menino, havendo dois cortes de cabelo distintos, correspondentes aos dois tipos. Ou guerreiros audazes, que Darcy viu serem "viris, enérgicos, avalentados, rebeldes e preguiçosos..." "sempre desocupados, contando casos e cantando, enquanto as mulheres e os velhos se matavam de trabalhar para sustentá-los" ou "os poucos tipos mansos, efeminados, dóceis, diligentes e operosos que haviam sido batizados de outra forma" (Ribeiro 1980). Esta segunda categoria compreendia os "cudinas, descritos por toda a documentação etnológica sobre os antigos Guaikuru..." como "homossexuais que adotavam quase inteiramente a conduta feminina: vestiam-se como mulheres, andavam e se sentavam como elas, simulavam a menstruação, dedicavam-se às artes femininas chegando a ser grandes "virtuoses" e até se casavam". Os papéis eram moldados pelos nomes e provavelmente formavam o caráter segundo essas características opostas, sugere Darcy.

\section{Nomes, direito e substância}

Nomes, aspecto da sociedade a ser estudado, arte criativa, são também um direito. É preciso lembrar o quanto, ao longo da história e da geografia, foram proibidos ou abafados - e ainda o são - em virtude de leis hegemônicas. Evoco um ou outro traço dos nomes judaicos, como exemplo. Até o fim do século 
XVIII os judeus podiam escolher seus nomes - usavam o nome próprio e o do pai. Eram comunidades pequenas, nas quais todos se conheciam, como nas indígenas. Foi por essa época, porém, na Áustria, e em outros países depois, uma das formas de discriminação e racismo foi obrigar os judeus a usarem nomes de família - proibindo-os de usar nomes de localidades, como às vezes faziam, ou de famílias nacionais ilustres, considerados impróprios para estes supostos sub-cidadãos. Em alguns países os melhores nomes tinham que ser pagos por altos preços. Outros pejorativos eram baratos ou concedidos (como Corda de Galés, Galgenstrick ou Cabeça de Burro, Eselkopf). Judeus passaram a inventar alternativas, como nomes das tribos judaicas (Levi, Judah, Cohen), de ocupações, ou patronímicos, ou ao acaso, de outras famílias, quando isso não era proibido. Abreviaturas também foram usadas. Era costume identificar casas medievais, judaicas ou outras, por sinais distintivos, marcas simbólicas, pois nem todos sabiam ler; mas foram proibidas e substituídas por números.

Nomes de família hereditários existiram na China antiga, no século IV A.C. e em Roma, mas em muitos países europeus custaram a surgir, só depois do ano 1000. Nomes de família judaicos surgiram nos séculos X e XI. Quanto a proibições tradicionais, judeus ashkenazi dão nomes de parentes, mas só dos que já faleceram, e nunca de quem teve morte violenta. ${ }^{5}$

Meu nome judaico é Laila - pude escolhê-lo, e o quis porque significa Noite, tanto em árabe como em hebraico, é ecumênico. Para mim evoca dança, prazer e arte noturnas, leveza. Segundo cânones tradicionais, um homem doente precisa pronunciar o nome judaico da mãe em rezas de cura.

Vale a pena preservar nomes tradicionais juntamente com os nomes cidadãos, ou seja, nomes e sobrenomes brasileiros. Todos poderiam ser reconhecidos, oficiais ou não nos documentos brasileiros. É a sua poesia que deveria sempre ser parte do ar que respiramos.

\section{Coincidência: a Moça Sem Sobrenome}

$\mathrm{Eu}$ estava revendo este artigo no dia em que conheci a artista de teatro e cinema Camila Márdila, com o encantamento de pensar nela como meu duplo, a juventude reencontrada. Contou-me que nasceu sem sobrenome, pois a mãe, do Piauí, de Campo Maior, foi registrada apenas com o nome, Maria dos Remédios. Sonhava em ganhar um sobrenome ao se casar, mas apaixonou-se pelo pai de Camila, mineiro de Senador Firmino, que também tinha apenas o primeiro nome, Moizés Evangelista, embora viesse da família Pires Dias! Quando tiveram Camila, o sonho de um sobrenome aconteceu: Márdila em homenagem a uma menina que nasceu no hospital onde Maria dos Remédios trabalhava, um pouco antes de engravidar de Camila; ao qual acrescentaram Remédios Evangelista, combinando os nomes de pai e mãe, registrados os três

\footnotetext{
${ }^{5}$ Há muitas observações interessantes em Kaganoff (1977).
} 
em cartório como nome de família a ser transmitido às gerações futuras. Eis o começo de uma estirpe: Camila Márdila dos Remédios Evangelista.

\section{Referências}

Peggion, Edmundo Antonio (2007). "A classe dos nomes: a onomástica Amondáwa (Kagwahiva/RO)". In: Cabral, Ana Suelly Arruda Câmara e Aryon Dall'Igna Rodrigues (Orgs.). Línguas e culturas tupi. Campinas, SP, Curt Nimuendaju; Brasília: LALI/UNB, p.123-130.

Kaganoff, Benzion. C. (1977). A dictionary of Jewish names and their history. New York, Schocken Books.

Mindlin, Betty (1985). Nós Paiter, Petrópolis, RJ, Vozes. (2006). Diários da floresta. São Paulo, Terceiro Nome.

Ribeiro, D. (1980) Kadiwéu, Petrópolis, RJ, Vozes.

Data recebimento: $13 / 04 / 2015$

Data aceite: 15/07/2015 